\title{
Charles Taylor and Moral Realism: A Falsifiable Realism
}

\author{
Xuemei Wang \\ School of Philosophy, Beijing Normal University, Beijing, China \\ Email:15911088271@163.com
}

How to cite this paper: Wang, X. M. (2021). Charles Taylor and Moral Realism: A Falsifiable Realism. Open Journal of Social Sciences, 9, 389-402.

https://doi.org/10.4236/jss.2021.98027

Received: July 25, 2021

Accepted: August 24, 2021

Published: August 27, 2021

Copyright $\odot 2021$ by author(s) and Scientific Research Publishing Inc. This work is licensed under the Creative Commons Attribution International License (CC BY 4.0).

http://creativecommons.org/licenses/by/4.0/

\begin{abstract}
This paper aims to come to grips with the moral realism of Charles Taylor by focusing on the debate between realists and nonrealists. I believe that a close examination of Taylor's moral realism can express Taylor's critical attitude to contemporary moral philosophy, it also brings out a new way which can face to the challenges of nonrealism. Ruth Abby argues that Taylor's moral realism is different from two current popular realisms: strong and weak moral realism and she takes Taylor's moral realism as a falsifiable realism. But some of Taylor's commentators contend that his moral realism belongs to the strong side. However, there are also some claims that his realism is weak. I attempt to argue against those commentators and defend his moral realism as a falsifiable realism. As a result, the contribution of this paper is twofold. First, it reveals the defects of both strong moral realism and weak moral realism. Second, as a consequence, this analysis not only make us believe that Taylor's moral realism does not belong to strong or weak side, but also his attention to individual's moral life and experience has its own unique characteristic and superiority, It also illustrates the importance of good and why his realism is called a falsifiable realism.
\end{abstract}

\section{Keywords}

Charles Taylor, Moral Realism, Goods, Moral Philosophy, Moral Projectivism

\section{Introduction}

Charles Taylor is considered by Richard Rorty to be one of the twelve most important philosophers working in the contemporary world. Like Habermas, he has written extensively in a wide range of fields, including social philosophy, political theory, history of thought, philosophy of language, moral philosophy, and philosophy of religion. As a moral realist, Taylor is distinguished from the tradi- 
tional realists, because he doesn't get involved in the debate between realism and nonrealism directly, nor does he develop a systematic theory of moral realism. But his thoughts on moral realism have uniqueness; especially he attempts to reconcile strong realism with weak realism, resulting in what I consider to be a unique theory of realism: a falsifiable realism.

Charles Taylor illustrates the making of self identity by analyzing the relation between self and morality in the source of self, so Taylor's moral theory is closely connected with his analysis of selfhood. Meantime, it also shows that Taylor's moral refection by criticizing the modern moral philosophy in this argument. The most important critique that Taylor raises is that modern moral philosophy is no longer concerned with the nature of good life, but only simply regards morality as a the content of obligation, that is only concentrating on what it is to do is right rather than what it is good to be. Hence, it results in some problems of moral subjectivism, moral relativism and moral skepticism. One of the attempts that Taylor wants to do is reconstructing the moral ontology in order to solve these problems; therefore, it brings us to the issue of Taylor's moral realism. However, Taylor construct his realism theory not by trying to refute nonrealist theorists with analysis and argument but telling the long story of how the conception of the good for human beings has developed and his unique understanding of the reality of morality (Kerr, 2004).

The good plays vital role in Taylor's moral realism, he thinks that there are some goods are worthy than others not because of the choices or desires of individuals but because they are intrinsic. Some commentators take his realism as a strong moral realism according to it, while others regard it as a weak realism. I argue that both misunderstand Taylor's realism, it might be has some features of strong or weak realism, but it is a falsifiable realism rather than belongs to them. Taylor separates the wheat from the chaff in these two kinds of realisms and overcomes their respective defects. He admits there exist moral goods which are independent of individuals, but he also underline personal moral life and experiences, because it makes no sense that morality exists without human beings to know them. More than this, Taylor also illustrates that our moral judgments and statements, namely, our ordinary moral experiences might be erroneous and people rely on moral goods and can argue and get a account that why this experience is erroneous (Abby, 2000), which makes his moral realism become special. And I suggest that the falsifiable is better than the other two realisms, which can lead a new way that can deal with the question raised by moral nonrealism. About how to understand Taylor's falsifiable realism is my main task of this paper and I will also attempt to show what roles of moral goods are played in his realism theory.

\section{The Making of Moral Realism}

In the past twenty years or so the debate over moral realism has become a major focus of philosophical activity (Smith, 2000). It not only needs respond the question from external, such as moral nonrealism, but also deal with the debate from inside, therefore, it brings us lots of literature and opinions. At the same time, it 
also results in a ton of confusion. Although Taylor did not talk about the formation process of moral realism, I will try to outline it roughly here.

Moral realism is the central theory to meta-ethics. However, we still can't reach a consensus on what the moral realism is. Generally speaking, moral realists must believe that 1) we can get the knowledge of morality but these knowledge could be false, because we don't always have access to moral truth. 2) there are moral facts that are independent of human's interpretations and understanding (Chen, 2008). From 1) we can know that moral statements or judgments have cognitive content. For instance, moral judgement like "doing nothing to save sb-X from ruin" is morally wrong, is not just a expression of emotion or order, but is a true or false moral statement. On the contrary, non-cognitivists who are also moral nonrealists deny all cognitive characteristics of moral judgement, they argue that moral discourse just is the "projection" of subjective emotion or the expression of order. Due to their own obvious defects, non-cognitivism has been questioned. If moral claims sentences only express one's feeling, moral judgement will be easily fall into the mire of moral subjectivism, then sliding into moral relativism even moral skepticism, because they refuse the objects of moral judgement have moral properties, that is eliminating moral objectivity and universality. As consequence, there are no moral principles people can depend on and no right or wrong moral standard. People themselves become the source of morality, this is certainly unaccepted by us. There is no doubt that Charles Taylor is a cognivitist, it obviously can see that from "The whole way in which we think, reason, argue, and question ourselves about morality suppose that our moral reactions have these two sides: that they are not only "gut" feeling but also implicit acknowledgement of claims concerning their objects. The various ontological accounts try to articulate these claims. In other words, Taylor claims morality is not just our "gut" feeling, the objects we are concerning also have the properties to which the moral predicate refers.

As what I mentioned before, the important feature of cognitivism is that all moral judgement or claims sentences can be true or false; it can be reflected and justified by us. If moral discourse has truth-aptness, then it implies the desire for truth, it leads us to the question that how do we determine whether moral judgement is true or false, right or wrong? On this issue there are two positions of moral realism and moral nonrealism in the cognitivism (Gan, 2011). From 2) above, moral realists insist the existence of moral facts which are independent of individual's explanation, because it makes moral claims have objectivity which can avoid falling into subjectivism even skepticism. But moral nonrealism refutes this point, even though they think moral judgments have cognitive content. They suggest that moral realism faces serious difficulties.

\section{The Challenges to Moral Realism}

The typical critique is from John L Mackie's moral error theory; it is a theory that although most people in making moral judgment implicitly claim, among other things, to be pointing to something objectively prescriptive, these claims 
are all false (Mackie, 1977). His theory is regarded as the indirect ground for realism, which means most realism's thoughts are established in the process of opposing moral error theory. Mackie offers two arguments for considering our moral judgments and claims are all false. The first is argument from relativity: he points to the diversity of moral opinion, namely he believes that morality is distinct in different cultural, different social group and different era, thereby there is no objective morality and moral principles exist (Mackie, 1977). The second is argument from queerness. Mackie contends that it would be queer substances and qualities if there are moral values, because they are different from anything in the world, besides we must have unique moral organs or moral perceptual abilities to perceive them which are distinct from our general abilities that can know things. Mackies takes Plato's forms and moral intuitionism as example, he argues that Plato invents "the form of good" in order to affirm objective values and moral intuitionism creates the intuition to recognize these values. However it's queer and unconvinced measures (Mackie, 1977).

In fact, the upshot of moral error theory is that "we don't need moral facts to explain moral judgments or to explain anything else, moral facts, if there were any, would be explanatorily impotent. So we do better not to believe in them" (Kerr, 2004). Although Taylor regard moral error theory as cruder because its two arguments are less rigorous and too arbitrary, that is we cannot refuse the existence of a unified moral value because of the diversity of moral value system, nor can we deny its existence because the objective value is entity that is different from other things, it still gives a stimulation to moral realism to improve their views that they must solve the issues in metaphysics and epistemology so as not to fall into the trap of queerness.

Most realists develop their theory rely on the objection to moral error theory. But like Kerr said "Philosophers will always want to probe the weaknesses of doctrines that affirm the reality of objectivity in ethics" (Kerr, 2004). Thereby neither strong realism or compromised weak realism can dispel the doubts of nonrealism. I have already discussed the deficiencies of strong realism above, now I want to expound the problems that weak realists have to face. The central standpoint that weak realists hold is that they want to connect the subjective with the objective, in other words, they not only admit the objectivity of moral facts but also identify inevitable relation with subjective factors. It can solve the issue that moral facts as objective realities can neither be classified as empirical facts nor perceived by intuition completely.

The typical current weak realism theories belong to John McDowell and David Wiggins, they all maintain that moral values are secondary qualities and this concept is put forward by Locke. Locke distinguishes the primary and second qualities of objects, he argues that the primary quality is a property that never change in any circumstance, such as size, weight, extension and the identification of secondary qualities with "powers to produce various sensation in us", namely a secondary quality is a property the ascription of which to an object is not adequately understood except as true, if it is true, in virtue of object's dispo- 
sition to present a certain sort of perceptual appearance: specifically, an appearance characterizable by using a word for the property itself to say how the object perceptually appears (McDowell, 1988). What McDowell wants to emphasize is that the second quality is the interaction of subject and object, the qualities like color, sound, smell, etc are secondary. Hence McDowell and Wiggins both contend that morality is like the second quality, which is objective and real, but it can only be presented if it is associated with the individual.

In view of the above, weak realism does solve the big challenge to moral realism, namely moral values not only has objective foundation, but also does not need queer perception to grasp it. Whereas, the point seems to fail to persuade the enemies. The first difficulty that McDowell and Wiggins have to solve is the objective reality in their sense has deviated from traditional realism which requires objective reality must be independent of our desires or feelings. Nevertheless the subjects play an important role in this point that moral values are secondary qualities. The second problem is McDowell and Wiggins only lay stress on the secondary qualities is the result of objective factors and subjective factors, but they overlook illustration that how the subjective factor involve this process. Our sensory organ is a vehicle of secondary qualities of objects, eyes for the colour, nose for the smell, etc. Therefore if morality is like the second quality, what kind sensory organ can responsible for something like morality or values, I am afraid that we have to ask for the help of Hutcheson's moral sense. As consequence, it falls into identical predicament with moral intuitionism or or become the evidence of the rationality of queerness.

In order to solve this problem, Thomas Nagel intend to defend moral realism with the help of another weak realism theory. Nagel stress that moral facts, moral statements or moral judgments as objective realities do not mean they must be independent of human beings, but means that they are generally recognized by all rational agents (Gan, 2011). However, it leads us to another question why are moral facts accepted by all rational agents have objectivity. It also is the central point to Negal's realism, he believes that we can create an idealized process of rational deliberation (Carla, 2021) where moral judgments can be considered by rational agents who have to eliminate their own desires and interests. If some moral judgments are discussed and approved in this process, it implies that these moral judgments have legality, validity and objectivity. In other words, objective moral facts are not entities or substances which are independent of human beings, but are decided by an idealized process of rational deliberation, as long as it can pass this process, the objectivity will be affirmed and proved. Hence, Nagel's realism is called moral constructivism or procedural realism because of this feature. Nagel thought that his theory could provide a firmed support for moral realism, however in fact the theory has been questioned.

Some critics claim that the connotation of objectivity has been tampered with by moral constructivism (Gan, 2011). The traditional understanding to objectivity is in the ontological sense, but moral constructivism treats objectivity in more narrow way, they regard it as the result of internal coordination of the subject. 
Accordingly, strictly speaking, moral constructivism theory can't count as moral realism. They don't avoid responding this challenge, according moral constructivism, moral realism does not necessarily place moral values in an ontological position, because natural science or anti-metaphysical thoughts has destroyed something like the essence of Plato's idea, ontological objectivity has lost its persuasive power. Except this one, another challenge seems to attract more attention as well as more difficult to overcome, that is critique of idealized process of rational deliberation, especially the reason which plays significant role in that process. Critics doubt the reliability of this process, they contend that reason is given far more capability than itself and don't explain how reason has the mysterious ability that Nagel has given it. The debate about this is complicated, due to space limitations, I don't intend to talk about it in detail and that also is not our focus in this paper.

So far, I have talked about the making of moral realism theory and its challenges from nonrealism. I also have discussed its variant, strong and weak realism which attempts to fight for it, however, both have their own defects to defend moral realism. In order to defend moral objectivity, what strong realism is trying to do is not directly set the existence of normative entities, but assume that there are some internal relations between a moral property and a group of natural properties. Whereas it get caught up in Moore's open question argument, even though they can suppose that the internal relations is not a strict identity, but an epiphytic relationship, it also have caused another question that can't be answered by strong realists. Weak realists try to construct moral facts that contains both subjective and objective elements and attempts to remove the ontological objectivity. But it is accused that it is no longer moral realism, the reason I refer to in last chapter. To sum up, it seems that both strong and weak realism are not capable of solving the issues of moral realism, so I intend to introduce and analyze Charles Taylor's moral realism, I think his theory can open new gate to stalled realism.

\section{Taylor's Moral Realism}

Before discussing Taylor's theory, I want to sort out briefly the problems of moral realism again. It is often assumed that morality has an objectively valid authority over us, that is, it dictates that we act in a certain way, regardless of our accidental desires or tendencies. Thereby, moral realists believe that there exist moral facts which are independent of human mind so that people can make moral judgments according to it, furtherly, it can prove objective validity of morality (Xu, 2017). However, it brings corners which need to be solved by realists: The dichotomy of fact/value that means we can't deduce ought from fact, Moore's open question, Mackie's queerness and intractable moral disagreement (Huang, 2021). As a result, various solutions to these problems lead to different kinds of moral realism which regard themselves as the most orthodox and can provide a strong defense for moral realism. 
Charles Taylor has no intention of involving in these arguments about realism and defending realism, he might dissatisfied with the theory of current moral realism, thus he have had some comments on anti-realism, the traditional moral realism as well as the current popular realism, but he did not fall into these chaos, he just made his own realistic analysis of morality. Nevertheless, commentators still interpret his realism as strong or weak realism, they deny that Taylor created a new path for realism. I argue that Taylor's realism is different. $\mathrm{He}$ is committed to the third way of reconciliation: he not only recognizes the real existence of morality, but also emphasizes people's status and their moral experience. Moreover, Taylor's interpretation of realism also contains dissatisfaction with modern moral philosophy and criticism of naturalism, certainly, which are based on portrait of goodness and emphasis on the human ontology. Without doubt, the approach to maintain realism that Taylor takes is different from strong realism and weak realism, the former is obsessed with moral facts and moral objectivity and the latter considers morality as artificialities, for Taylor, The good plays a central role in his realism and the methods he adopts to expound to prove the reality of good have the features of moral phenomenology and hermeneutic. I will discuss in the next section. What's more, Taylor's realism which shows not only his deliberation of the nature of morality but the reflection to modern moral philosophy has its own distinguishing feature and superiority.

\subsection{The Reality of Good}

Taylor contends that modern moral philosophy construes morality in a more narrow way where the only thing they care about is what is to be right rather than what is to be good, they define the content of obligation rather than the nature of the good life, it doesn't leave a conceptual place for a notion of good (Taylor, 2001). It is a big mistake that ignoring the importance of goods, Taylor believes that good is not the source of irrelevance or confusion as the contemorary mainstream philosophy thinks, but vital and real, it plays a critical role in every regarding human life, not only in shaping the most profound moral response in ordinary life, but also in revealing or establishing their identity as moral agents (Xie, 2012). It thus appears in Taylor's point that good can responsible for the moral objectivity, whereas anti-realists suggest that both good and morality belong to the right side of Humean dichotomy of fact/value, which means good even can't prove its own objectivity let alone can be a source of moral objectivity.

So Taylor has to deal with the criticism to prove the reality of good, but he has neither like other traditional realists seeking to substances or entities of good to ensure the objectivity, nor like the weak realists view good as a property of projection. Taylor attempts to demonstrate the reality of good and its validity in moral world in his own way. Taylor's defence of the reality of goods begins with the concern of moral phenomenology about humans and their moral experience and holds that the study of the field of values must be complemented by empirical first-person research of moral life, as he says, "What we need to explain is 
people living their lives" (Taylor, 2001). I will analyze whether these demonstration can convince us to believe the good is real, if he solve the issue of reality of good, the moral objective validity can be guaranteed.

Taylor claims that strongly valued goods command the respect of individuals because of their intrinsic value; they are experienced as making calls or demands upon individuals, rather than being freely or arbitrarily chosen by them (Taylor, 2001). It means that there exist the independent-mind goods, this is also the reason why some commentators who interpret Taylor's moral realism as strong realism that it seems that he presupposes the entities of goods which are independent of individuals similar to Plato's theory of idea or the Christian God, Quentin Skinner criticizes Taylor's position of moral realism on this account and claims that Taylor attempts to rebuild a traditional, theistic moral ontology, which will lead to coercion and intolerance and harm a pluralistic society (Skinner, 1991). I have to say that this is a serious misconstrue of Taylor's theory, because Taylor is opposed to the kind of traditional realism or strong realism, he contends that the traditional realism has been objectively allied with natural science model in creating a false picture of the issue of moral goods (Taylor, 2001), they all are devoted to seeking the source of moral response and belief from the external world independent of the self, and both ignore the moral response and ability of the subject self which are taken seriously by Taylor's realism theory.

From Taylor's attack on the natural science and projectivism we know that it is impossible to discuss moral world without human, because it would make no sense to try to explain moral life in abstraction from one of its central forces (Taylor, 2001). Taylor stresses that our argumentation and discussion of morality are always inextricably connected with our deepest moral response. The most reliable moral horizon is not founded on something outside our intuition but is based on our strongest intuition. It is impossible and meaningless for us to explain behavior only from the perspective of the observer through some kind of "neutral" theoretical language, because it does not help the subject to understand his own thoughts, feelings and actions (Xie, 2012). We can't help asking if moral values are not products of our projection, then how to infer the reality of good from human's perception of good.

Taylor construes that what is real is what you have to deal with, what won't go away just because it doesn't fit with your prejudices, thereby what you can't help having recourse to in life is real, or as near to reality as you can have a good command of at present (Taylor, 2001). In Taylor's view, the strongly valued goods are what you can't help having recourse to in life which can help you make deliberation and judgements to some situations or decide what feelings do you have to other people. What Taylor is trying to say here is not only value terms is closely related to the purposes and uses of our life, but also the reality of these goods are supported by our ordinary moral experience. it is absurd to discuss morality in isolation from life in order to conform to a naturalistic position, 
because these strongly valued goods play a central role in explaining and understanding self and others such as assessing one's conduct, making moral choice, evaluating your life, etc.

What's more, what needs to be highlighted here is that "cannot help" is not like the inability to stop blinking when you through a sudden danger, or your incapacity to contain your irritation at someone breaking your favorite glass (Taylor, 2001). It means that these strongly valued goods you depend on make the best sense of what you're doing. By this token, strongly valued goods do exist independently of choices or desires of human beings, As Ruth Abby says, "The fact that individuals may feel that these goods derive their worth not merely from being valued by them but believe, rather, that they are valued because they are worthy, need commit Taylor neither to the proposition that these goods actually do exist nor that they are valuable in themselves" (Abby, 2000).

Taylor demonstrates the reality of goods with human's moral life experience, the best account of the reality of goods can not be separated from our moral life. He shows that goods are not our subjective projection but the framework that we can't help depending on when we cope with various cases in order to make the best sense of what we are doing, thereby the framework of the good are objective and real. We sense in the very experience of being moved by some higher good that we are moved by what is good in it rather than that it is valuable because of our reaction. We are moved by seeing its point as something infinitely valuable. We experience our love for it as a well-founded love (Taylor, 2001). Namely, we experience goods as being worthy of their admiration and respect for reasons that do not depend on their choice of them but their intrinsic value.

It seems to describe how people experience their moral life like weak realism, therefore, some scholars attribute Taylor's realism, which focuses on moral experience, to weak realism. However, it is also a distortion of him. Weak realism takes realism as a description of how people experience their moral life but does not accept this as a true description of the moral world. This feature of moral experience has no bearing on its interpretation of reality (Abby, 2000). This standpoint is not in line with Taylor, although he claims to offer a phenomenology of moral life, to give account of how individuals experience the goods in their lives, he insists that reality is the feature of moral world not the artificial products (Abby, 2000), and gives ontological significance to human moral experience.

So far, I have clarified that Taylor's realism is neither strong realism nor weak realism. I argue that Abby's falsifiable realism is the most proper interpretation of Taylor's realism, because it lies between strong and weak realism, taking into account the superiorities of both, but her illustration of falsifiable realism is still confusing, I attempts to make it clear and indicate that why Taylor's realism is a falsifiable realism.

\subsection{A Falsifiable Realism}

Taylor admits that there exist moral facts in moral world and people have the 
ability to understand these moral facts and make judgments about moral propositions based on them, whether true or false. However, either admitting moral facts or proving strongly valued goods have independent existence are not the purpose of Taylor's realism but the strategy he adopts to make the best sense of our lives. Taylor is committed to pursue the broadest moral concern that is how we should live our life rather than the principles, or injunctions, or standards which guide action are focused by modern moral philosophy which accepts the attitude of natural science research. In other words, modern moral philosophy only concerns about the establishment of a set of neutral external standards by which people can do something right, and ignores our need for a meaningful life. To Taylor, "'Making the best sense' here includes not only offering the best, most realistic orientation about the good but also allowing us best to understand and make sense of the actions and feelings of ourselves and others" (Taylor, 2001).

How do we make the best sense of our lives? Taylor believes that this is based on our critical and reflective thinking ability, in view of this, if there is no human subject to discuss morality, morality will not exist. He construes that in human affairs, except for the terms based on critical reflection and corrected for the mistakes we can detect, there is no better measure of reality that makes sense of our life (Taylor, 2001). Namely, human subjects and morality are intertwined, since human subjects exist, some ways will be more advanced or valuable than others to expound the reality of morality. Because the human subjects with critical and reflective thinking ability can use conceptual system and experience to describe and judge a moral situation.

But it brings us to the issue that you may not yourself be the best authority (Kerr, 2004). There is no objectivity in moral judgment made by people on their own, this is also the reason why natural science is maximally freed from anthropocentric conceptions and insists on examining morality or goods with a neutral attitude or the perspective of the third-person. But from the perspective of the observer, we cannot really understand the reality of morality or good, and understand what is meaningful life, even though their third-person explication seems to be more reasonable, the use of non-explanation in the first-person has proved impossible to eradicate. So for Taylor, the reality of morality or good is closely related to human subject, especially human's self-interpretation, which is also the main content of Taylor's falsifiable realism.

In order to fight back against the Platonism and the natural science model of alliance, Taylor thinks that the problem that value is not a part of reality needs to be reexamined. As I mentioned earlier, he thinks that in order to make our life have the best meaning, the best measures of reality are those terms which on critical reflection and after correction of the errors we can detect. In other words, when we think about our moral actions, evaluate our own and other's personalities and feelings, reactions and try to understand and explain them, we will come to the most practical and insightful terms for these matters, and what these terms 
show, It will be true and objective for us here (Yin, 2014).

Hence, Language plays an critical role in this argument. According to Taylor, language is the medium through which human beings express themselves and construct themselves, it can make people form distinct objects of consciousness and make things that people care about possible. Not only that, when language expresses something, it is actually constructing something. For example, when you want to express a certain feeling in proper terms, it will make you have a deeper understanding of this feeling, once you find some terms that can describe that feeling, the feeling is formed as well, at the same time, you will know yourself better. That is to say, by accepting language, we have the concepts of meaning that influence us, and these concepts help to make up our experience (Qiao, 2014). By the same token, human beings are not simple existence who always inquiry and interpret themselves or everything about themselves, but their interpretation is not separated from reality, conversely this interpretation has a constructive influence on reality. To a certain extent, our interpretations of ourselves is constitutive of what we are, by accepting language, we have the concept of meaning that affect us, and these concepts help to shape our experience (Qiao, 2014).

So our search for moral reality is actually a construction of self-interpreting, for Taylor, it is no longer an axiom to seek moral truth based on moral facts, what he adopts is the path of moral phenomenology and hermeneutics, that is, we can have the best account of the current moral situation, and what the best account shows is true and objective to us.

What kind of account can be called the best account? Taylor believes that the terms we use to describe human behavior should have to make sense across the whole range of both explanatory and life uses. In his opinion, for the purpose of theoretical explanation, it is preposterous to ignore the terms of life uses. As he says "It seems to me that the various theories of moral judgments as projections, and the attempts to distinguish 'value' from 'fact', fall afoul of this best account principle" (Taylor, 2001). The terms we select to expound behavior have both explanatory and life uses significance, and will produce the best account of any given age. Moreover, there is no scientific or natural epistemological or metaphysical consideration in this best account, and these terms are the most realistic and insightful, just like the best exposition of the physical world, they will find real physical phenomena, these terms also indicate the reality of morality or values (Taylor, 2001).

However, it should be noted that the best account of the moral field emphasized by Taylor is not equal to the moral truth, because the language interpretation of the moral field by the modern self is likely to be wrong, so it needs to rely on individuals' critical reflection ability to try to make the best account of the current situation. In other words, we need to conduct extensive discussion on morality based on the strongly valued goods that are independent of individuals, and then constantly correct the mistakes that may appear in it, so as to approach 
the goods and the moral truth. Therefore, Taylor's moral realism is called falsifiable realism, which is close to strong realism, but human subjects can interpret and construct moral values based on the goods. Although there is the possibility of making mistakes that can be corrected according to our reflective ability. we can explore in trial and error, move forward in error correction, and constantly approach the goods.

\section{Conclusion}

As far as Taylor is concerned, whether it is anti-realism, strong realism or weak realism, which are all infringed by the contemporary popular naturalism model. In this picture, human beings and their activities are generally regarded as the objects of scientific research, and hold that morality or good is not a part of reality. In order to cater to this popular way of thinking, anti-realism denies that our moral judgments are cognitive, so there is no truth or false, and it is not a moral proposition, but disguised as a moral proposition. The strong realism seeks the external moral entity, or reduces the moral fact to a natural fact or extends it to a natural feature in order to maintain the objective validity of morality, which inevitably falls into a kind of mysticism or fails to explain how it is normative. Weak realism regards morality and "value" as projection to the world, which can only be presented with the help of our subjective cognition so as to overcome the dilemma of strong realism. However, this stance still denies the existence of morality and value are independent of human beings and denies the ontological existence of morality.

On the contrary, Taylor has a strong faith in moral ontology, he insists that all such moral philosophies are inevitably subjectivist and radical anthropocentric, when they talk about morality without ontology. Taylor also indicates that ontology is rarely explored and revealed due to its complexity and the suppression of natural scientific theories, but this does not mean that moral ontology as well as moral value is fictitious, there are various reasons can account for this phenomenon, some are distrust to ontology, some are the impacts of epistemology. However, for Taylor, our moral responses are inextricably bound up with ontology and they cannot be separated from ontological commitments, which make our moral reactions meaningful and also mean we can't interpret morality in a "neutral" attitude. And that Taylor holds that we can't offer a satisfactory conclusion about what the moral noumena or human noumena is, he believes that it is a big adventure to attempt to solve this question and he also agrees with that his dissecting of ontology is enough to prove that we moderns do indeed rely on certain tentative, hesitating and fuzzy commitments (Taylor, 2001).

Taylor is a conciliationist philosopher. He tries to seek a middle position between two extremes: strong realism and weak realism. Therefore, I want to restate my argument is that Taylor's realism is either strong or weak but falsifiable. Falsifiable realism is his third path, which not only shows his unique understanding of the reality of moral and value, but also shows his dissatisfaction with na- 
turalism research mode. Taylor believes that our moral world is distinguished from the physical world; the complexity of moral issues is beyond the scope of description and explanation of natural science theory. Therefore, our human reality can no longer be understood in terms suitable for physics. Falsifiable realism no longer inquiry what are the impersonal universal moral facts on which moral judgments can be based, but focuses on personal moral life and experience. In his view, the strongly valued goods that we have to resort to frequently in life are real, and it exists independent of our choices or desires. We make the best account for a certain situation at present, and what these explanatory terms show is true or objective to us. But Taylor does not deny that our interpretation of moral value is erroneous, he contends that this kind of errors can refer to the goods, and through critical reflective power of human subjects, it can be constantly corrected, trying to achieve the truth.

\section{Conflicts of Interest}

The author declares no conflicts of interest regarding the publication of this paper.

\section{References}

Abby, R. (2000). Charles Taylor (pp. 27, 29-31). Acumen Publishing. https://doi.org/10.1017/UPO9781844653188

Carla, B. (2021). Constructivism in Metaethics. In E. N. Zalta (Ed.), The Stanford Encyclopedia of Philosophy (Spring 2021 ed.). Metaphysics Research Lab, Stanford University. https://plato.stanford.edu/archives/spr2021/entries/constructivism-metaethics

Chen, L. (2008). An Introduction to Ethics (p. 87). Peking University Press.

Gan, S. P. (2011). The Development Trend of Moral Realism (pp. 61, 67). The Journal of Yunnan University Social Sciences, 10, 60-68.

Huang, Y. (2021). Moral Realism: An Approach to Zhu Xi's Virtue Ethics. In Shanghai Confucianism College of Fudan University (Ed.), Modern Confucianism. The Commercial Press.

Kerr, F. (2004). The Self and the Good: Taylor's Moral Ontology (pp. 89, 91, 93). In R. Abby (Ed.), Charles Taylor (pp. 84-104). Cambridge University Press. https://doi.org/10.1017/CBO9780511610837.004

Mackie, J. L. (1977). Ethics: Inventing Right and Wrong (pp. 37, 40, 109). Pelican Books.

McDowell, J. (1988). Values and Secondary Qualities (p. 168). In G. Sayre-McCord (Ed.), Essays on Moral Realism (pp. 166-181). Cornell University Press.

Qiao, C. X. (2014). Charles Taylor's Thought of Philosophical Anthropology (pp. 89-90). Intellectual Property Publishing House.

Skinner, Q. (1991). Who Are "We"? Ambiguities of the Modern Self. "Symposium on Charles Taylor's Sources of the Self”. Inquiry, 34, 133-153.

https://doi.org/10.1080/00201749108602249

Smith, M. (2000). Moral Realism. In H. LaFollette (Ed.), The Blackwell Guide to Ethical Theory (pp. 15-37). Wiley-Blackwell. https://doi.org/10.1111/b.9780631201199.1999.00003.x

Taylor, C. (2001). Sources of the Self (pp. 3-4, 20, 56-59, 74). Harvard University Press. 
Xie, Y. (2012). On Charles Taylor's Concept of Good (p. 23). Ph.D. Thesis, Fudan University.

Xu, X. D. (2017). Moral Realism and Moral Truth (p. 236). Tsinghua Studies in Western Philosophy, 3, 212-271.

Yin, J. P. (2014). Self-Interpretation and the Good-On Charles Taylor's Thought of Identity Ethics (pp. 30, 35). Ph.D. Thesis, Heilongjiang University. 